\title{
Barriers to accessing and using contraception in highland Guatemala: the development of a family planning self-efficacy scale
}

This article was published in the following Dove Press journal:

Open Access Journal of Contraception

27 April 2016

Number of times this article has been viewed

\author{
Emma Richardson' \\ Kenneth R Allison ${ }^{1,2}$ \\ Dionne Gesink' \\ Albert Berry ${ }^{3}$ \\ 'Dalla Lana School of Public Health, \\ University of Toronto, ${ }^{2}$ Public Health \\ Ontario, ${ }^{3}$ Department of Economics, \\ Munk Centre for International \\ Studies, University of Toronto, \\ Toronto, ON, Canada
}

\begin{abstract}
Understanding the persistent inequalities in the prevalence rates of family planning and unmet need for family planning between indigenous and nonindigenous women in Guatemala requires localized explorations of the specific barriers faced by indigenous women. Based on social cognitive theory, elicitation interviews were carried out with a purposive sample of 16 young women, aged 20-24 years, married or in union, from the rural districts of Patzún, Chimaltenango, Guatemala. Content analysis was carried out using the constant-comparison method to identify the major themes. Based on this qualitative study, the following barriers are incorporated into the development of a self-efficacy scale: lack of knowledge about and availability of methods, fear of side effects and infertility, husbands being against family planning (and related fears of marital problems and abandonment), pressure from in-laws and the community, and the belief that using contraception is a sin. This is the first evidence-informed self-efficacy scale developed with young adult, indigenous women that addresses the issue of family planning in Latin America.
\end{abstract}

Keywords: indigenous, marginalized populations, elicitation interviews, social cognitive theory

\section{Introduction}

Latin America is a region characterized by inequality, and social and economic inequality in Guatemala is among the highest in the Americas, with the wealthiest quintile of the population holding $58 \%$ of the total income, compared to the bottom quintile that holds only $3 \%$.

Unmet need for family planning is defined as the proportion of currently married women who do not want any more children but are not using any form of family planning or who want to postpone their next birth for two years but are not using any form of family planning. ${ }^{2,3}$ In Guatemala inequality in unmet need for family planning, along with other maternal health indicators, is evident along rural/urban, indigenous/ nonindigenous lines. ${ }^{4}$ There are 153 maternal deaths per 100,000 live births, and this rate is three times worse for indigenous vs nonindigenous women (211 vs 70, respectively). ${ }^{5}$ The total fertility rate for indigenous women is 4.5 compared to 3.1 for Ladina women (Spanish-speaking women of mixed Spanish and indigenous heritage). ${ }^{6}$ Contraceptive use by indigenous women (54\%) in Guatemala is significantly lower than that of their Ladina counterparts $(28 \%){ }^{6}$ This difference persists even for indigenous women who have immigrated to the city or who live in the same household with Ladinos in rural towns..$^{7-11}$

Early research on family planning in Guatemala showed persistent gaps between Ladinas and indigenous women in terms of contraceptive knowledge and behavior,
Correspondence: Emma Richardson Dalla Lana School of Public Health, University of Toronto, 155 College Street, 6th Floor, Toronto, ON, M5T 3M7, Canada Tel + I 4169936389

Fax + I 416978 I883

Email emma.richardson@utoronto.ca
Open Access Journal of Contraception 2016:7 77-87

(c) (1) (8) ๑ 2016 Richardson et al. This work is published and licensed by Dove Medical Press Limited. The full terms of this license are avalabble at https://www.dovereres.com/ cc. work you hereby accept the Terms. Non-commercial uses of the work are permitted without any further permission from Dove Medical Press Limited, provided the work is properly attributed. For permission for commercial use of this work, please see paragraphs 4.2 and 5 of our Terms (https://www.dovepress.com/terms.php).
Dovepress

http://dx.doi.org/10.2147/OAJC.S95674 
particularly in the rural areas. ${ }^{12}$ These trends have been monitored over time, showing increasing gaps along ethnic lines; however, past work to understand these differences is not yet complete. ${ }^{13}$ The hypothesis that this was due to differential access (ie, distance to health facilities providing contraceptive services) between indigenous and Ladino populations was originally supported when access to services was found to be a significant correlate with contraceptive use for the Mayan population, once sociodemographic variables were controlled for. ${ }^{13}$ However, this was later refuted when a study linking household to facility-level data showed that physical distance to family planning providers was not significantly different between Ladinas and indigenous women. ${ }^{14}$ An alternative hypothesis emerged suggesting that the quality of services may be driving differential access, with Mayans being offered discriminatory services in inferior facilities by health professionals who, for the most part, do not speak their native language. ${ }^{14,15}$ The most recent study of ethnic inequality in Guatemala lends support to this hypothesis, finding that "not speaking Spanish accounts for the largest portion of ethnic differentials" in met need for modern contraceptives. ${ }^{11}$ Nevertheless, there was a residual difference in modern contraceptive use between indigenous and Ladina women, which could not be explained by any of the quantitative factors included and probably relates to social and cultural influences that are not possible to capture in quantitative proxy measures. ${ }^{11}$ This paper thus explores these social, cultural, and normative factors that may help explain ethnic differences in the unmet need for family planning.

Unmet need for family planning can be understood from a health behavior perspective as the gap between women's reproductive intentions and their contraceptive behavior. ${ }^{16}$ This concept thus lends itself to exploration under the lens of health behavior theory, which strives to understand the constructs that determine behavior and explain discrepancies between intentions and behavior. Social Cognitive Theory, from this family of health behavior theories, recognizes "the triadic influence between behavioral, cognitive and environmental influences," which is appropriate in Guatemala where environmental and structural issues are salient. ${ }^{17,18}$

Applying Bandura's Social Cognitive Theory to contraceptive behavior, young women's contraceptive behavior is understood to depend pivotally on self-efficacy for contraception. Self-efficacy is "the conviction that one can successfully execute the behavior required to produce the outcome" and is measured by understanding people's confidence in overcoming progressively difficult barriers to the successful achievement of a particular behavior. Self-efficacy is behavior- and situation-specific, and "self-efficacy scales developed and validated with one population may not be applicable to other populations." ${ }^{19}$ In order to understand the contraceptive behavior in young indigenous women from rural Guatemala, it is therefore critical to first understand what the particular barriers to contraception are in this context.

This is the first time a situation-specific self-efficacy scale has been developed in relation to contraception in Latin America. Levinson's adolescent self-efficacy scale has been informative and used in North American research regarding self-efficacy for contraception in the United States in adolescent girls, ${ }^{20-22}$ college-age females, ${ }^{23}$ male and female black college students, ${ }^{24}$ and male and female adolescents in Quebec, Canada. ${ }^{25}$ These studies have demonstrated the utility of the self-efficacy construct in predicting contraceptive behavior and highlighting areas that can be impacted through intervention. ${ }^{20,22,25}$ This same scale has also been used in Hong Kong to examine contraceptive self-efficacy in adult women, ${ }^{26}$ although no adaptations were made despite Levinson's scale having been developed for use with adolescent populations in the United States. ${ }^{20,21,27}$

The barriers facing young, indigenous women in highland Guatemala who are married or in union are nevertheless very different from those of adolescents or unmarried women attending college in the United States, and therefore, Levinson's scale is not directly applicable in this rural Guatemalan context. Peyman et $\mathrm{al}^{28}$ developed a self-efficacy scale based on focus groups with married Iranian women; however, their scale lacks clarity in terms of specific barriers and may not be appropriate for an indigenous context. The family planning self-efficacy scale described in this paper was developed with a population consistent with those surveyed in large national demographic and health surveys. These surveys are nationally-representative household surveys that provide data for a wide range of monitoring and impact evaluation indicators in the areas of population, health, and nutrition used globally to determine rates of unmet need for family planning. ${ }^{29}$

The purpose of this paper is to present results from elicitation interviews with indigenous Guatemalan women of childbearing age and the resulting Guatemalan family planning self-efficacy scale. Benefits and limitations of this method are discussed. This is the first evidence-informed contraceptive self-efficacy scale consistent with Bandura's social cognitive theory and developed specifically with adult indigenous women in rural Guatemala as opposed to nonindigenous adolescents in North America. ${ }^{20,21,25}$ The 
barriers to using family planning discussed in this paper have implications for reducing unmet need for contraception among indigenous women in Guatemala and in similarly marginalized groups worldwide.

\section{Methods}

In the Department of Chimaltenango, there are 454,000 Kaqchikel women, making up $76.2 \%$ of the total population of 595,800 people. ${ }^{30}$ Elicitation interviews were carried out with 16 young women, aged 20-24 years, married or in union, from two rural districts of Patzún, Chimaltenango, Guatemala: El Llano and Las Mercedes. According to the general guidelines for this qualitative descriptive approach of elicitation research, approximately 15 interviews should be carried out, until there is saturation from each target group, "when no new responses are elicited," with approximately half of the participants having performed the behavior under investigation. ${ }^{31}$ Women were purposively sampled such that users $(n=8)$ and nonusers of contraception $(n=8)$ were equally represented, and among the nonusers of contraception, half $(n=4)$ wanted to delay childbearing for $>2$ years, consistent with the definition of unmet need for family planning (Table 1).

The semistructured interview guide was based on suggested questions for elicitation research from the literature. ${ }^{31,32}$ Women were also asked about their contraceptive knowledge, behavior, and sociodemographic variables, primarily using questions adapted from previous instruments such as the demographic and health surveys. ${ }^{33}$ The interview guide was translated from English to Spanish by the primary researcher. The research team, including both a local research assistant and a research coordinator, helped to simplify the language in the research guide to ensure it would be better understood by participants. For those participants requiring it, the research assistant translated the interview guide into

Table I Participant characteristics related to definition of unmet need for family planning $(n=16)$

\begin{tabular}{lll}
\hline & $\begin{array}{l}\text { Wanted next } \\
\text { birth within } \\
\text { 2-years }\end{array}$ & $\begin{array}{l}\text { Wanted to delay } \\
\text { next birth by } \\
\text { 2-years or more }\end{array}$ \\
\hline $\begin{array}{l}\text { Currently using modern } \\
\text { method of family planning } \\
(n=8)\end{array}$ & 2 & 6 \\
$\begin{array}{l}\text { Not currently using modern } \\
\text { method of family planning } \\
(n=8)\end{array}$ & 4 & $4^{*}$ \\
\hline
\end{tabular}

Notes: *indicates that these participants are classified as having an unmet need for family planning. Family planning is the use of modern methods such as the pill, injectables, implants, condoms, spermicide, IUD, and male or female sterilization.
Kaqchikel (the native Mayan language), and the research coordinator back-translated this into Spanish, in order to confirm the accuracy of the translation.

Recruitment was carried out by a young, female, Kaqchikel research assistant, in collaboration with local facilitators from the Renacimiento non-governmental organization in Guatemala, which provides health extension services in the rural districts where the research was conducted. Within rural districts, women in the age range of 20-24 years (inclusive) were pre-identified and then approached in their homes to explain the nature of the study. In the rural district of El Llano where the majority of interviews were carried out, every woman in this age range was approached, resulting in the successful recruitment of 13 of 15 potential participants (one was never found at home, despite several repeat visits, and the other refused to participate on the grounds that she was too busy). In the second rural district of Mercedes, potential participants were approached in their homes on a random basis and asked initial screening questions in order to ensure the various categories of users and nonusers of contraception were recruited. Informed consent was sought prior to beginning the interviews, consistent with research ethics approval obtained from both the University of Toronto and the University del Valle in Guatemala. The interviews occurred mostly in women's homes during the day when their husbands were absent and, when privacy was a concern, in the local health centers. The Kaqchikel research assistant was present during all interviews to introduce the concepts of the research to participants and translate between Kaqchikel and Spanish when necessary.

The elicitation interviews were audio-recorded, transcribed verbatim, with original comments recorded both in Kaqchikel and in Spanish, and analyzed in both languages. Interviews were carried out between May and July, 2013, and continued until saturation was reached in terms of the themes raised relating to accessing and using contraception. ${ }^{34}$ Content analysis was carried out by the investigator and research team using the constant-comparison method, which "is concerned with generating and plausibly suggesting (but not provisionally testing) many categories, properties, and hypotheses about general problems. ${ }^{35}$ According to this qualitative descriptive approach, a "comprehensive summary of events" was created "in the everyday terms of those events. ${ }^{36}$ Codes were developed and revised by the research team to ensure accuracy and validity and then organized into themes relating to the barriers for accessing and using family planning. NVivo 9 software was used to manage the analytic process. The barriers discussed by the participants in 
accessing and using family planning were distilled as much as possible into one-phrase obstacles and then integrated in the family planning self-efficacy scale.

\section{Results}

\section{Participants}

Sixteen indigenous women, who identified themselves as Kaqchikel, participated in the elicitation interviews. The mean age of the participants was 22.4 years old, with a range of 20-24 years (Table 2 ). Women of this age range were specifically recruited because we were interested in examining the decisions of women early in their reproductive lives but were advised by community partners that interviewing adolescents had particular ethical challenges. Also, since indigenous people in Guatemala have life expectancies that are 13 years shorter than their Ladina counterparts and pregnancy during adolescence is common, these women are already approaching the middle of their reproductive lives. ${ }^{37}$ Participants were from two rural districts of Patzún, Chimaltenango, Guatemala: Las Mercedes (three) and El Llano (13).

\section{Interrelated barriers}

Three interrelated barriers were identified: concern about social chastisement for using family planning, one's husband being against family planning, and fear or experience of side effects.

Table 2 Descriptive characteristics of participants $(n=16)$

\begin{tabular}{lll}
\hline Characteristic & Number & Percentage \\
\hline Age, years & 1 & \\
20 & 1 & 6 \\
21 & 5 & 6 \\
22 & 8 & 31 \\
23 & 1 & 50 \\
24 & 10 & 6 \\
Highest level of education completed & \\
Sixth grade or less & 5 & 63 \\
Some middle school* & 1 & 31 \\
Completed high school & & 6 \\
Number of living children & 2 & \\
0 & 7 & 12 \\
I & 7 & 44 \\
2 & & 44 \\
Pregnant & 4 & 25 \\
Yes & 12 & 75 \\
No & & \\
Current family planning method & 7 & 44 \\
Depo-Provera & 1 & 6 \\
Condoms & 8 & 50 \\
None &
\end{tabular}

Note: ${ }^{\text {ane }}$ participant had one child who had died. *indicates the equivalent of sixth to ninth grade.
Many women described fear of others finding out about their use of family planning. Initially in interviews women expressed these concerns in highly broad terms. For example, because others "will criticize me," "think badly of me," "look at me," "make me feel badly," or "talk about me." When probed about what others will say, more specific critiques were articulated. For example, others will say, "she doesn't want to give children to her husband," "she can't maintain a family," "she's not a woman ... because she can't have lots of children," "she does not have the will to receive her children," or even "she must be looking to go with another" (ie, have an affair). Most of these comments allude to the identity and worth of women, at least in a traditional sense, being highly bound with providing many children to her husband. The opinion of others holds great weight because this is a communal community with shared resources and high respect for elders. There are several ways women justified how they break with restrictive expectations relating to women's worth being bounded closely by her exhibited ability to bear children for her husband. Participants expressed wanting a better life for themselves and their children, often describing this in relation to difficult upbringings they had, particularly as girls who faced gender-based discrimination. One participant thus said she thought using family planning was good "so the girl does not suffer, nor the mother." Another participant spoke of using family planning as being about protecting her body and her "self." Further ways women spoke of being able to resist criticism related to understanding others' harsh comments as being routed in jealousy. Some did not worry about others finding out about their family planning status since they figured "the majority" of others were also using family planning or that, over time, the spacing between their children would make it obvious they are using family planning anyways. One woman delineated temporally her decision as different from that of her mother-in-law because she had "already lived her life and we haven't; we are just starting, so the conversation is just between us [her and her husband]." Interestingly, this same couple chose to relieve pressure from the husband's mother through him telling her they would be using natural methods, which they believed she would find less objectionable than using the modern method of the pill. Several women were able to insulate themselves from critique because they felt that although others, particularly in-laws, tried to involve themselves in the couple's decision to use family planning, this was really a decision they make as a couple.

Having one source of support (or the absence of a barrier) can act as a buffer against the effects of other barriers. For example, a husband's support was helpful for withstanding social pressure and chastisement: 
I've been told that, 'one marries to have children, and when you can't have children, you are not women.' That is what I've been told, but I don't give that importance. It's good to be in agreement in the couple. My husband helps and encourages me. People say what they say but they don't see what I lived with my family and I want to have something, and provide education to my daughters. That's my ... good that my partnership is like that.

On the contrary, if a woman did not have the support of her husband, critiques from others were hypothesized to cause problems in the relationship:

It's good to make the decision as a couple, because if only a woman and not him, and that comes: they all start to talk ... Then it starts, you start having problems in the couple.

Misinformation, fear of side effects, and infertility were common among the participants. For example, one woman described:

Some say you can't have children later, yes, that's what they say (laughter), we haven't proven this ... According to what they say, if you use that [contraception], it can give you cancer.

Often side effects were described based on having heard about another woman's experience:

A sister of my sister-in-law said that she used the copper T. She said she got bacteria in the place where the method was. It got infected and they operated on that part. So, yes, it causes illness.

Others dismissed the side effects described by others as rumor:

Well, many say that the planning that some use, that it harms them; their stomachs hurt or it gives them cancer in their stomach. So they don't want to use those methods and they keep giving birth each year, because of hearing those rumors or gossip that others tell them, but I think it's not like that.

In total, 12 participants discussed fear of side effects, but only a minority (two) experienced side effects directly, and just one of these discontinued family planning due to side effects. Directly experienced side effects were attributed to Depo-Provera and included headaches, which did not cause discontinuation, and stomach aches that for another participant did contribute to her discontinuation of family planning. The side effects that women mentioned being concerned about included stomach aches, headaches, cancer, irregular menstruation, bacterial infections, weight gain, weight loss, pain in feet, infertility, and illness in general. Typically, women heard second-hand accounts of side effects, which were often enough to dissuade them from using family planning, although they wondered about the accuracy of these concerns. For example, one participant explained:

They say it causes cancer, but who knows? I don't know. I

don't know if it's true or lies. Who knows?

Family planning is used to prevent or achieve pregnancy. Social pressures to have children may cause some women to hide their use of family planning, sometimes even from their husbands. Hiding the use of family planning to prevent pregnancy, combined with limited contraceptive options, may push some women to use and remain using contraceptive methods despite experiencing side effects or other adverse reactions. For example, one participant who used Depo-Provera (3-month injection) chose this method because it is more discreet and she could do so without her husband knowing. She might have been reticent to switch methods even if she experienced side effects. A husband being a barrier to using contraceptives amplifies the effect of limited options for family planning (extension services in the community offered only natural methods, condoms, and the Depo-Provera injection). Stories of these side effects, which reach women contemplating using family planning, no doubt have an amplified effect to negatively influence the uptake of a family planning method for preventing pregnancy.

\section{Experience of obstacles is not straightforward}

The barriers in the scale represent summaries of the types of issues faced by individual women and are not nuanced enough to represent the full experience of participants. For example, the statement asking of one's confidence to "Use a family planning method even if my partner does not want me to" probes only generally at the influence of the husband's opinion. Another important dimension to consider is the reason(s) behind the husband's opposition to family planning, which are diverse, all with different implications for potential programming and policy (Table 3 ).

In relation to this barrier, one woman whose husband had previously been against even discussing family planning explained he was convinced of the merits of spacing children and using modern contraception to achieve this through special sessions directed at men at his work. The participant attributed these sessions with his willing- 
Table 3 Perceived reasons for husband's objection to family planning

\begin{tabular}{ll}
\hline Husbands' objection & Participant comments \\
\hline He would like more & $\begin{array}{l}\text { They don't use family planning because their } \\
\text { children }\end{array}$ \\
husbands forbid it or because their husbands \\
we is worried to have children.
\end{tabular}

Note: $[P]$ refers to the participant, $[I]$ refers to the interviewer and arefers to paraphrased responses.

ness to begin broaching the topic with her and ultimately with their joint decision to start using a modern form of contraception.

Another common barrier was the belief that family planning is a sin. Eleven of 16 participants in this study talked about the understanding that using contraception is a sin as a barrier to family planning, despite only five reporting attending church (four Catholic and one Evangelical). However, for various reasons several participants countered this discourse or felt themselves to be exempt (Table 4).

\section{Applicability of self-efficacy in the indigenous Guatemalan context}

Participants showed varying levels of confidence in overcoming particular barriers during elicitation interviews (Table 5).

\section{Proposed family planning self-efficacy scale}

The barriers integrated into the family planning scale (Table 6) relate to the following issues: lack of knowledge, availability, or communication about family planning methods, availability of contraceptive methods, fear of side effects and infertility, husbands being against family planning (and related fears of marital problems and abandonment), pressure from in-laws and the community, and the belief that using contraception is a sin. Conceptually, the 18 -item scale may be understood to group around four elements or subscales of self-efficacy for family planning. These four subscales are composed of items relating to access (questions 1 and 3), communication (questions 2, 4, 5, 6, and 16), social support (questions 7, 8, 9, 10,11, 12, and 18), and assertiveness for family planning (questions 13, 14, 15, and 17).

\section{Discussion}

The development of this self-efficacy scale represents a first step in the application of localized self-efficacy for family planning research in rural Guatemala. This research provides insights as to how localized elicitation interviews can influence the understanding of particular obstacles to carrying out a particular behavior in a given context. ${ }^{19,38}$

The proposed family planning self-efficacy scale developed from this study is, as expected, quite different from the one developed by Levinson. ${ }^{20}$ Levinson's scale, developed with American adolescents, served as an important reference for the types of barriers that might be faced in this different population and thus for possible probes to include in elicitation interviews. However, the scale from this study addresses different types of pressures particular to the life-stage and context of indigenous young married women in rural Guatemala, with ensuing marital, communal, and traditional expectations, as opposed to more individual-type barriers in Levinson's scale that pertain more directly to the assertiveness of the participant in her relationship with her boyfriend. ${ }^{20}$

Individual elicitation interviews are critical to successfully develop self-efficacy scales that are relevant to the local context. The barriers found to be important in this context are suggestive of potential barriers in other contexts but are not exhaustive. For example, a draft scale developed for this study based on a review of the literature included questions to capture whether the direct cost of obtaining family planning methods was prohibitive. The quantitative research of Ishida et $\mathrm{l}^{11}$ hypothesized that indigenous Guatemalan women may feel discriminated against by their health service providers who do not speak their native language. Due to relatively new 
Table 4 Participants discuss resistance of belief that contraception is a sin

\begin{tabular}{|c|c|}
\hline $\begin{array}{l}\text { Grounds for resistance of idea that } \\
\text { contraception as a sin }\end{array}$ & Participants comments \\
\hline \multirow[t]{4}{*}{$\begin{array}{l}\text { Having more children than one can care } \\
\text { for is also a sin }\end{array}$} & $\begin{array}{l}\text { As my father in law says, one part is that [family] planning is a sin, but as my husband was saying, } \\
\text { a greater sin is having children that }[\ldots] \text { we don't have enough to give them the things that children } \\
\text { should be given, so we decided to plan, yes. }\end{array}$ \\
\hline & $\begin{array}{l}\text { According to what l've heard all methods are a sin, because they say that's what God sends, one has } \\
\text { to receive, but, at times one does not have the possibility to provide for all of them. }\end{array}$ \\
\hline & $\begin{array}{l}\text { Well the Bible says it is good, but thinking about it, living it, well one can't, because one is of scarce } \\
\text { resources and can't manage with so many children. }\end{array}$ \\
\hline & $\begin{array}{l}\text { They say you can't do anything because in their mind it's a sin and the Bible says that God created } \\
\text { man and woman to have a family. Well yes, but it also says in the Bible that you're not going to } \\
\text { give your child a stone if he asks for bread, so there it talks about the family. But as they don't } \\
\text { understand, they are closed-minded that it's not good, so for this reason they don't use a method. }\end{array}$ \\
\hline $\begin{array}{l}\text { Using contraception is not a sin compared } \\
\text { to abortion }\end{array}$ & $\begin{array}{l}\text { According to what they say, they've told me that it's a sin, but I say it's a sin when you're pregnant } \\
\text { and you think about aborting; there yes, because you have a human in your belly, but not if you take } \\
\text { care of yourself from the beginning. I say this is not a sin; that's what l've understood. }\end{array}$ \\
\hline $\begin{array}{l}\text { Contraception is not a sin if you know you } \\
\text { are not pregnant when you start using it }\end{array}$ & $\begin{array}{l}\text { With natural methods one can't, can't abort. And with contraceptives one can cause an abortion. Or } \\
\text { someone who has not used contraceptives, and without realizing it, is expecting, and then they plan } \\
\text { or use methods. This is the risk of using contraceptive methods. With natural methods you can't } \\
\text { abort. But if one knows she isn't pregnant she can use contraceptive methods, uhum, to not become } \\
\text { pregnant. }\end{array}$ \\
\hline Approval from a community leader & $\begin{array}{l}\text { The priest says one has to plan naturally, take care of oneself, but sometimes this doesn't work. } \\
\text { Because, for example, I can't because my period is not consistent. }\end{array}$ \\
\hline $\begin{array}{l}\text { Cannot plan family naturally because } \\
\text { menstrual cycle is inconsistent }\end{array}$ & $\begin{array}{l}\text { You're a 'one-a-year'er' [Añera] people said, since I would get pregnant very quickly... [In church] } \\
\text { they told us that it's a sin to use [contraception] ... abort or anything else is a sin ... but one time } \\
\text { the pastor's wife asked me, 'are you taking care of yourself?' Yes, I told her, yes because my daughter } \\
\text { is still very little and another one will be so hard. 'Yes,' she said, 'better that way so when she's } \\
\text { bigger you can have another one. There's no problem,' she said. That's why I was using it. }\end{array}$ \\
\hline
\end{tabular}

expansions of national health strategies in Guatemala and the provision of Kaqchikel services by doctors and nurses in the communities where interviews were carried out, these potential barriers were not found to be important and were dropped from our scale.

Having to sign medical forms to access family planning methods was not described as a barrier in this study. However, it is important to consider that the husbands of women in the study knew whether their wives were using family planning or not. We were transparent in our recruitment about the potential risk of inadvertently revealing a woman's family planning status to her husband. Therefore, women hiding their use of family planning from their husbands were likely to self-select out of the study. In one rural district, the local nurse preferred for us not to approach women in the community because she knew many women were hiding their family planning use from their husbands. Therefore, we proceeded with recruitment in a different rural district. This makes it difficult to estimate the proportion of women who are using family planning without the knowledge of their husbands. Only one participant had previously used family planning without her husband knowing, although this was no longer the case at the time of the interview. Reports from local nurses who have tended to victims of domestic violence and stories told in the interviews suggest that a woman using family planning without her husband knowing is fairly common, with real risks of violent reactions from her husband if he finds out. For this particular group, where privacy and confidentiality are even more critical, having to sign for contraceptives could present a barrier.

Results of the study show how the presence or absence of one barrier may have a reinforcing or weakening effect on the influence of other obstacles. Self-efficacy scales list obstacles as if they were free-standing and independent, but this research suggests the possible presence of interaction effects that are not captured by asking about the confidence in overcoming individual barriers and would have to be empirically tested. This phenomenon is evidenced by the overlap of three kinds of barriers found in this study: concern about social chastisement for using family planning, the husband being against family planning, and fear or experience of side effects. The interrelatedness of individual barriers has implications for policy. For example, the resolution of barriers relating to fear and experience of side effects is multifaceted: more options of methods and information about side effects and their likelihoods should be made more accessible (such 
Table 5 Participants discuss their degree of confidence in overcoming barriers

\begin{tabular}{ll}
\hline Barrier (n) & $\begin{array}{l}\text { Participants degree } \\
\text { of confidence in } \\
\text { overcoming barrier (n) }\end{array}$ \\
\hline $\begin{array}{l}\text { Husband against family } \\
\text { planning }(n=10)\end{array}$ & High (3)
\end{tabular}

Medium (2)

Low (5)

Fear of side effects High (7) $(n=12)$
Examples of participant comments

Yes, I had confidence in myself because my baby was really small when I had the next one [child]. So, yes, as he [my husband] did not want to [use contraception], I said to my mother and she said 'if you are ok with it, go,' she said, and I went [and used family planning]. [P]

Well, as a couple it's the decision of both of you, but if the husband is not... no, does not approve [of using family planning], right? Well you have the right to decide for yourself, because it's your life. It's your body and not his. [P]

It would be hard for me [to use family planning if my husband were against it]. Well maybe with care, but I do say I would have problems, and always ... but it's difficult because it's good to make the decision as a couple. Because if alone, and you go and he doesn't, then there's a lot of problems. You can even despair sometimes, and like that. But in my case if he doesn't understand then it's him, and he'll see the consequence with the kids ... [P] Yes, I think that he disagrees and I can't command him or decide by myself...Yes, as I said I would like to plan, but as I said my family doesn't want me to, nor does my husband. They're in disagreement [with me] and that's how it is. [P]

In any case it's good. But yes, both have to be in agreement, with the husband and the wife, then you can. If only the woman, almost no. For my part, I wouldn't do that because, if one day he found out it's a problem. [P]

I'd say I wouldn't. Because he would realize ... There would be a fight because we don't have the same opinion. [P]

Yes, I still plan to use it for another two years. [P]

Despite the pains it could give you? [I]

Yes, because with my first baby I didn't use [contraception], then after, just like that we were taking care of ourselves, and with one moment of carelessness one can become pregnant. When one is planning, not anymore; I mean one is not scared of becoming pregnant again. [P]

Low (5) No, I wouldn't like to use [contraceptive methods]. No, because if l'm going to use, suddenly l'll get sick. Since sometimes it makes people ill after, like this harms them. I'm not sure what it does to your stomach with an injection, right? So that causes another illness, so for that reason I think I won't use it. [P]

Because some women say that, that it gives them a headache or the menstruation comes and goes, comes and goes, and for others that it goes away right away. This is what they say. That's why l'm scared to use it. [P]

Note: $[P]$ refers to the participant and $[I]$ refers to the interviewer.

that women know about and can switch between methods more easily if they experience side effects), but women will not take advantage of the array of choices if they are limited to the options that can be used in secret. Thus, key areas of work are to educate young husbands and influential others (mothers in law, etc) and to help young women develop the skills to convince their husbands if they want to use family planning.

Due to the obstacles mentioned, and not mentioned, by the indigenous women in the study presented here, there is evidence that distance to health services is not prohibitive for them nor do they find service provision to be discriminatory. However, the barriers included in the proposed self-efficacy scale probably relate to "unexplained" ethnic differentials in previous quantitative studies, which are primarily due to social and cultural factors. ${ }^{11}$ Since extant qualitative literature about the barriers to family planning for Ladino populations in Guatemala is sparse, it is hard to make a direct comparison to those found as important for the indigenous population in this study. In her mixed methods study of a predominantly Ladino peri-urban community of Guatemala City, Asturios de Barrios ${ }^{41}$ found that the unmet need for contraception was associated with a "paradigm of silence" that discourages discussion between spouses about reproductive decisions and "favors large families, which are considered the will of God." In the previous studies from Guatemala, many women report their ideal family size to be "God's will." "39-41 Ward ${ }^{42}$ found that in Guatemala, "distrust of family planning on religious grounds" was voiced by both Evangelical Protestants and Catholics. Lindstrom et a ${ }^{8}$ used network analysis to show that in Guatemala "social ties to urban or international migrants are associated with a greater 
Table 6 Family planning* self-efficacy scale questionnaire

\begin{tabular}{|c|c|}
\hline $\begin{array}{l}\text { How confident do you feel in your ability to } \\
\text { do each of the following activities }\end{array}$ & $\begin{array}{l}\text { Confidence } \\
\text { rating }\end{array}$ \\
\hline $\begin{array}{l}\text { I. Obtain information about different kinds of family } \\
\text { planning methods? }\end{array}$ & 12345 \\
\hline 2. Talk about different family planning methods? & 12345 \\
\hline $\begin{array}{l}\text { 3. Obtain a family planning method even if you have to } \\
\text { wait in long lines? }\end{array}$ & 12345 \\
\hline $\begin{array}{l}\text { 4. Discuss how many children you want to have with } \\
\text { your partner? }\end{array}$ & 12345 \\
\hline 5. Discuss family planning methods with your partner? & 12345 \\
\hline 6. Discuss family planning methods with your friends? & 12345 \\
\hline 7. Know other people who use family planning methods? & 12345 \\
\hline $\begin{array}{l}\text { 8. Use a family planning method even if you don't discuss } \\
\text { it with your partner? }\end{array}$ & 12345 \\
\hline $\begin{array}{l}\text { 9. Use a family planning method even if your partner } \\
\text { does not want you to? }\end{array}$ & 12345 \\
\hline $\begin{array}{l}\text { 10. Use a family planning method without your partner } \\
\text { knowing? }\end{array}$ & 12345 \\
\hline $\begin{array}{l}\text { II. Use a family planning method even if your } \\
\text { mother-in law does not want you? }\end{array}$ & 12345 \\
\hline $\begin{array}{l}\text { 12. Use a family planning method even if your parents } \\
\text { do not want you to? }\end{array}$ & 12345 \\
\hline $\begin{array}{l}\text { 13. Use a family planning method even if your are } \\
\text { afraid of side effects? }\end{array}$ & 12345 \\
\hline $\begin{array}{l}\text { 14. Use a family planning method even if you experience } \\
\text { side effects? }\end{array}$ & 12345 \\
\hline $\begin{array}{l}\text { 15. Use family planning even if you believe that family } \\
\text { planning is a sin? }\end{array}$ & 12345 \\
\hline $\begin{array}{l}\text { 16. Convince your partner that you should use family } \\
\text { planning? }\end{array}$ & 12345 \\
\hline $\begin{array}{l}\text { 17. Continue to use family planning even if people } \\
\text { in your community find out? }\end{array}$ & 12345 \\
\hline $\begin{array}{l}\text { 18. Use a family planning method even if your neighbors } \\
\text { criticize you? }\end{array}$ & 12345 \\
\hline
\end{tabular}

Notes: *Family planning was explained as being modern methods such as the pill, injectables, implants, condoms, spermicide, IUD and male or female sterilization. Confidence rating: $\mathrm{I}=$ not at all confident, $2=$ not very confident, $3=$ moderately confident, $4=$ very confident, $5=$ completely confident.

likelihood of modern contraceptive use among married women." These potential barriers and facilitators were also found as important for the indigenous women interviewed in this study, suggesting that some of same factors may influence contraceptive adoption by both Ladinas and indigenous women in Guatemala, although the barriers may be more strongly felt by Mayans.

The scale's reliability and validity need to be tested empirically. For example, predictive validity of the scale could be examined by assessing if women's confidence in overcoming these barriers correlates with contraceptive behavior, as would be predicted by social cognitive theory. The four hypothesized subscales relating to access, communication, social support, and assertiveness for family planning suggest that the scale may be multidimensional, but these conceptual groupings would have to be pilot tested and validated. Exploratory and confirmatory factor analysis could be performed in a quantitative study to see how the items load onto these four factors suggested by conceptual groupings.

The proposed scale intentionally employs simple, repetitive language for use in poor, rural areas where women are unlikely to have much formal education. An important question remains about how much the concept of confidence will be salient to indigenous women in this context and whether they will be able to express their confidence numerically, particularly given typically low numeracy and literacy levels. A promising outcome of this research is that varying degrees of confidence in overcoming particular barriers are discernible from participants' responses. If using numbered scales to express confidence proves too challenging for participants, alternatives exist such as using visual representations of different levels of confidence, for example, circles of progressively larger size. ${ }^{38}$ Alternatively, the application of self-efficacy scales might have to involve a higher degree of interpretation than is customary on the part of the researcher, in order to assign numerical equivalents of confidence expressed through verbal responses.

The elicitation interviews formed the basis for developing the self-efficacy scale, which is appropriate to the local context of rural districts from this medium-sized rural community in Guatemala. Caution is therefore advised before using this scale directly in another developing country context. The barriers discussed here are hypothesized to apply in other family planning research settings with marginalized populations in developing countries.

The rural districts included in this study are ideal for researching certain aspects of unmet need for family planning because culturally appropriate, confidential services appear to be available, so it is possible to probe more specifically the cultural and social reasons behind unmet need for family planning.

\section{Conclusion and policy implications}

Despite most participants (ten of 16) expressing the desire to wait two years or more before the birth of their next child, many barriers exist in this rural, Guatemalan context, which inhibit young women from using family planning. These barriers sometimes overlap in ways that amplify individual effects and complicate programming and policy solutions.

Important strides have been made with the provision of culturally appropriate extension services through the national 
health system, which women find convenient and have made family planning more accessible. The fact that language and discrimination were not mentioned by participants reflects this. However, this study highlights several policy options for improving reproductive health services, including providing a greater array of methods, ensuring privacy and confidentiality, and emphasizing that women can switch between methods in the case of complications. This study finds popular notions and rumors about exaggerated side effects to be prevalent, indicating that the provision of timely information about real side effects could be helpful.

The barrier of husbands' opposition is so salient for many of the women with unmet need for family planning that prioritizing this would be important in order to enhance family planning selfefficacy. There are two potential approaches that could be taken: in the longer term, programs and policies that improve gender equity and women's confidence in their own power within the relationship would be critical. But even in the shorter term, with inequitable gender relations as they are, important strides could be made through improving the family planning knowledge of young husbands. Programs that invite men to special sessions in their own small communities are unlikely to be successful due to the tabooed nature of the topic and existing social pressure against family planning. Men might fear attending due to potential chastisement. However, programs and information that reach men in their more habitual environments, such as their places of work, could prove highly effective.

Indigenous women in Guatemala, who experience higher levels of unmet need for family planning, will need more than improved availability of family planning services in order to close the gap in contraceptive prevalence levels with Ladinas. Programs that target inequitable gender relations and educate young husbands about the merits and mechanics of family planning may be particularly fruitful, in addition to the continued expansion of high-quality and confidential reproductive health services.

\section{Authors' contributions}

ER was the principal investigator of the study and led the writing of this manuscript. KRA, AB, and DG helped to conceive of and plan the study, supported the analysis, and helped in writing the drafts of the manuscript. All authors contributed toward data analysis, drafting and revising the paper and agree to be accountable for all aspects of the work.

\section{Disclosure}

The authors report no conflicts of interest in this work.

\section{References}

1. Haub C, Gribble J. The world at 7 billion. Popul Bull. 2011;66(2):1.

2. Mills S, Bos E, Suzuki E. Unmet Need for Contraception. Washington, DC: World Bank; 2010.

3. Westoff C. New Estimates of Unmet Need and the Demand for Family Planning: DHS Comparative Reports Number 14; 2006. Calverton, MD.

4. Figueroa W, Lopez F, Remez L, Prada E, Drescher J. Early childbearing in Guatemala: a continuing challenge. Issues Brief (Alan Guttmacher Inst). 2006;5(1):1-30.

5. Kols A. Reducing unmet need for family planning: evidence-based strategies and approaches. Outlook. 2008;25(1):1.

6. Ministerio de Salud Publica y Asistencia Social. Informe Preliminar: Encuesta Nacional de Salud Materno Infantil. [Public Health and Social Services Ministry. Preliminary report: National Maternal and Child Health Survey. Santo Domingo: Public Health and Social Services Ministry] Santo Domingo: Ministerio de Salud Publica y Asistencia Social; 2009.

7. Lindstrom DP. Internal migration and contraceptive knowledge and use in Guatemala. Int Fam Plan Perspect. 2006;32(3):146-153.

8. Lindstrom DP, Muñoz-Franco E. Migration and the diffusion of modern contraceptive knowledge and use in rural Guatemala. Stud Fam Plann. 2005;36(4):277-288.

9. De Broe S, Hinde A, Matthews Z, Padmadas SS. Diversity in family planning use among ethnic groups in Guatemala. J Biosoc Sci. 2005; 37(3):301-317.

10. De Broe S, Hinde A. Diversity in fertility patterns in Guatemala. Popul Space Place. 2006;12(6):435-459.

11. Ishida K, Stupp P, Turcios-Ruiz R, et al. Ethnic inequality in Guatemalan women's use of modern reproductive health care. Int Perspect Sex Reprod Health. 2012;38(2):99-108.

12. Bertrand JT, Pineda MA, Santiso R. Ethnic differences in family planning acceptance in rural Guatemala. Stud Fam Plann. 1979; 10(8-9):238-245.

13. Bertrand JT, Seiber E, Escudero G. Contraceptive dynamics in Guatemala: 1978-1998. Int Fam Plan Perspect. 2001;27(3):112-136.

14. Seiber E, Bertrand J. Access as a factor in differential contraceptive use between Mayans and Ladinos in Guatemala. Health Policy Plan. 2002;17(2):167-177.

15. USAID. Increasing Access to Family Planning Among Indigenous Groups in Guatemala. Washington, DC: Health Policy Initiative; 2008.

16. Loaiza E, Biddlecom A. Millenium Development Goal Indicators: Goal 5 - Improve Maternal Health. Available from: http://mdgs.un.org/ unsd/mdg/Metadata.aspx? IndicatorId $=0 \&$ SeriesId $=777$. Accessed February 18, 2014.

17. Glanz K, Rimer B. Theory at a Glance: A Guide for Health Promotion Practice. Bethesda, MD: U.S. Department of Health and Human Services, National Institutes of Health, National Cancer Institute; 2005.

18. Bandura A. The self system in reciprocal determinism. Am Psychol. 1978;33(4):344-358.

19. Maibach E, Murphy DA. Self-efficacy in health promotion research and practice: conceptualization and measurement. Health Educ Res. 1995;10(1):37-50.

20. Levinson RA. Contraceptive self-efficacy: a perspective on teenage girls' contraceptive behavior. The Journal of Sex Research. 1986; 22(3):347-369.

21. Levinson RA. Reproductive and contraceptive knowledge, contraceptive self-efficacy, and contraceptive behavior among teenage women. Adolescence. 1995;30(117):65-85.

22. Levinson RA, Wan CK, Beamer LJ. The contraceptive self-efficacy scale: analysis in four samples. J Youth Adolesc. 1998;27(6):773-793.

23. Heinrich LB. Contraceptive self-efficacy in college women. J Adolesc Health. 1993;14(4):269-276.

24. Wright C. Factors Associated with Contraceptive Behavior among Black College Students [PhD]. Oregon: University of Oregon; 1992. 
25. Bilodeau A, Forget G, Tétreault J. L'auto-efficacité relative a la contraception chez les adolescentes et des adolescsents: la validation de la version française de l'échelle de mesure de Levinson [Contraceptive self-efficacy for adolescents: Validation of the French version of Levison's Scale]. Can J Public Health. 1994;85:115-120. French.

26. Ip W, Sin LL, Chan DS. Contraceptive self-efficacy and contraceptive knowledge of Hong Kong Chinese women with unplanned pregnancy. J Clin Nurs. 2009;18(17):2416.

27. Davis CM, Yarber WL, Bauserman R. Handbook of Sexuality-Related Measures. 3rd ed. New York: Routledge; 2011.

28. Peyman N, Hidarnia A, Ghofranipour F, et al. Self-efficacy: does it predict the effectiveness of contraceptive use in Iranian women? East Mediterr Health J. 2009;15(5):1254-1262.

29. MEASURE DHS. DHS Overview. Available from: http://www measuredhs.com/What-We-Do/Survey-Types/DHS.cfm. Accessed February 14, 2014.

30. UNDP. Cifras para el Desarrollo Humano [Statistics for Human Development]. Chimaltenango: UNDP; 2011. Spanish.

31. Montaño DE, Kasprzyk D. Theory of reasoned action, theory of planned behavior, and the integrated behavioural model. In: Glanz K, Rimer BK, Viswanath K, editors. Health Behavior and Health Education. 4th ed. San Franciso, CA: Jossey-Bass; 2008:67-92.

32. Middlestadt SE, Bhattacharyya K, Rosenbaum J, et al. The use of theory based semistructured elicitation questionnaires: formative research for CDC's prevention marketing initiative. Public Health Rep. 1996;111(suppl 1):18-27.

33. ICF International. Demographic and Health Surveys MethodologyQuestionnaires: Household, Woman's, and Man's. Available from: http://www.measuredhs.com/publications/publication-DHSQ6-DHSQuestionnaires-and-Manuals.cfm. Accessed February 18, 2014.
34. Marshall MN. Sampling for qualitative research. Fam Pract. 1996; 13(6):522-525.

35. Glaser BG. The constant comparative method of qualitative analysis. Social Problems. 1965;12:436-45.

36. Sandelowski M. Focus on research methods-whatever happened to qualitative description? Res Nurs Health. 2000;23(4):334-340.

37. Elías S. Guatemala. In: Mikkelsen C, editor. The Indigenous World 2013. 1st ed. New York, NY: IWGIA; 2013:78-87.

38. Bandura A. Guide for constructing self-efficacy scales. In: Pajares F, Urdan T, editors. Self-efficacy Beliefs of Adolescents. 5th ed. Greenwich, CT: Information Age Publishing; 2006:307-337.

39. Metz B. Politics, population, and family planning in Guatemala: Ch'orti' Maya experiences. Hum Organ. 2001;60(3):259.

40. Da Silva ML, Gonçalvez IR, Temer M. Comportamiento de mujeres y susparejasreferentes a la planificación familiar [Family planning behaviour of women and their partners]. Investigación y Educación en Enfermería. 2010;28(2):195-203. Spanish.

41. Asturias de Barrios L, Mejia de Rodas I, Nieves I, Matute J, Yinger NV. Unmet Need for Family Planning in a Peri-Urban Community of Guatemala City. Washington, DC: ICRW; 1997.

42. Ward, VM, Bertrand, JT and Puac F. Exploring sociocultural barriers to family planning among mayans in guatemala. International Family Planning Perspectives. 1992;18(2):59-65.
Open Access Journal of Contraception

\section{Publish your work in this journal}

Open Access Journal of Contraception is an international, peerreviewed, open access, online journal, publishing original research, reports, reviews and commentaries on all areas of contraception. In addition to clinical research, demographics and health-related aspects, the journal welcomes new findings in animal and preclinical studies

\section{Dovepress}

relating to understanding the biological mechanisms and practical development of new contraceptive agents. The manuscript management system is completely online and includes a very quick and fair peer-review system. Visit http://www.dovepress.com/testimonials.php to read real quotes from published authors. 